\title{
A Visualization of a Socio-Ecological Model for Urban Public Mental Health Approaches
}

\author{
Antonis A. Kousoulis * and Isabella Goldie \\ Mental Health Foundation, London, United Kingdom
}

Keywords: mental health, social determinansts of health, public health, socio - ecological system, urban health

\section{INTRODUCTION}

According to the latest data from the Global Burden of Disease, over 1 billion people globally are affected by mental and addictive disorders, which cause $19 \%$ of all years lived with disability worldwide (1). It is clear that such an extensive issue requires an urgent and committed public health effort. To that end, a range of population-level approaches have emerged, though the frameworks used and adopted vary widely.

\section{FROM GENOME TO EXPOSOME}

OPEN ACCESS

Edited by:

Ashwani Kumar Mishra,

All India Institute of Medical

Sciences, India

Reviewed by:

Melinda Jane Goodyear,

Monash University, Australia

*Correspondence:

Antonis A. Kousoulis

akousoulis@mentalhealth.org.uk

Specialty section:

This article was submitted to

Public Mental Health,

a section of the journal

Frontiers in Public Health

Received: 15 January 2021

Accepted: 24 March 2021

Published: 13 May 2021

Citation:

Kousoulis AA and Goldie I (2021) A

Visualization of a Socio-Ecological

Model for Urban Public Mental Health

Approaches.

Front. Public Health 9:654011.

doi: 10.3389/fpubh.2021.654011
In recent years, a broad social agenda of psychiatric genetic research has emerged highlighting that genes account for a minority of our emotional and behavioral development, leaving the majority determined by social and physical environmental influences (2). Mental health must therefore be considered a dynamic state, whereby individual psychosocial development is influenced by multiple layers of intersecting social and environmental factors.

This starts in the womb with the mental and physical health status of mothers during pregnancy impacting the developing fetus. The very early years are greatly affected by parental bonding and the home environment. Thereafter, factors such as neglect or abuse in childhood; unemployment, poverty, and physical health problems in adulthood; and levels of social and community connectedness in later life all have a part to play in influencing an individual's ability and opportunity to access mental health protection, such as can be found in positive relationships, quality employment, and healthy living conditions. This picture is often complicated by the role of issues such as intergenerational trauma and the far-reaching and sustained impact of adversity in childhood, which suggests that upstream interventions are critical when taking a public mental health approach (3).

These factors (an indicative range of which is presented in Figure 1) can and often do have a cumulative and intersecting effect across the course of life. Exposure to adverse experiences can be particularly common and clustered within some families and communities as well as specific settings, such as schools and workplaces, that are already experiencing other destabilizing factors. Hence, in many ways one's postal code is more important than one's genetic code (4), and the term "exposome" has been proposed as a new paradigm to encompass the totality of human environmental (meaning all non-genetic) exposures from conception onward, complementing the genome, and impacting human health (2). It is therefore crucial that if mental health problems are to be prevented, the social, economic, health, and ecological environment in which they are developing needs to be addressed (5). Understanding how these factors influence risk and how this can be mitigated is vital, as is communicating them in an accessible, visual way. 


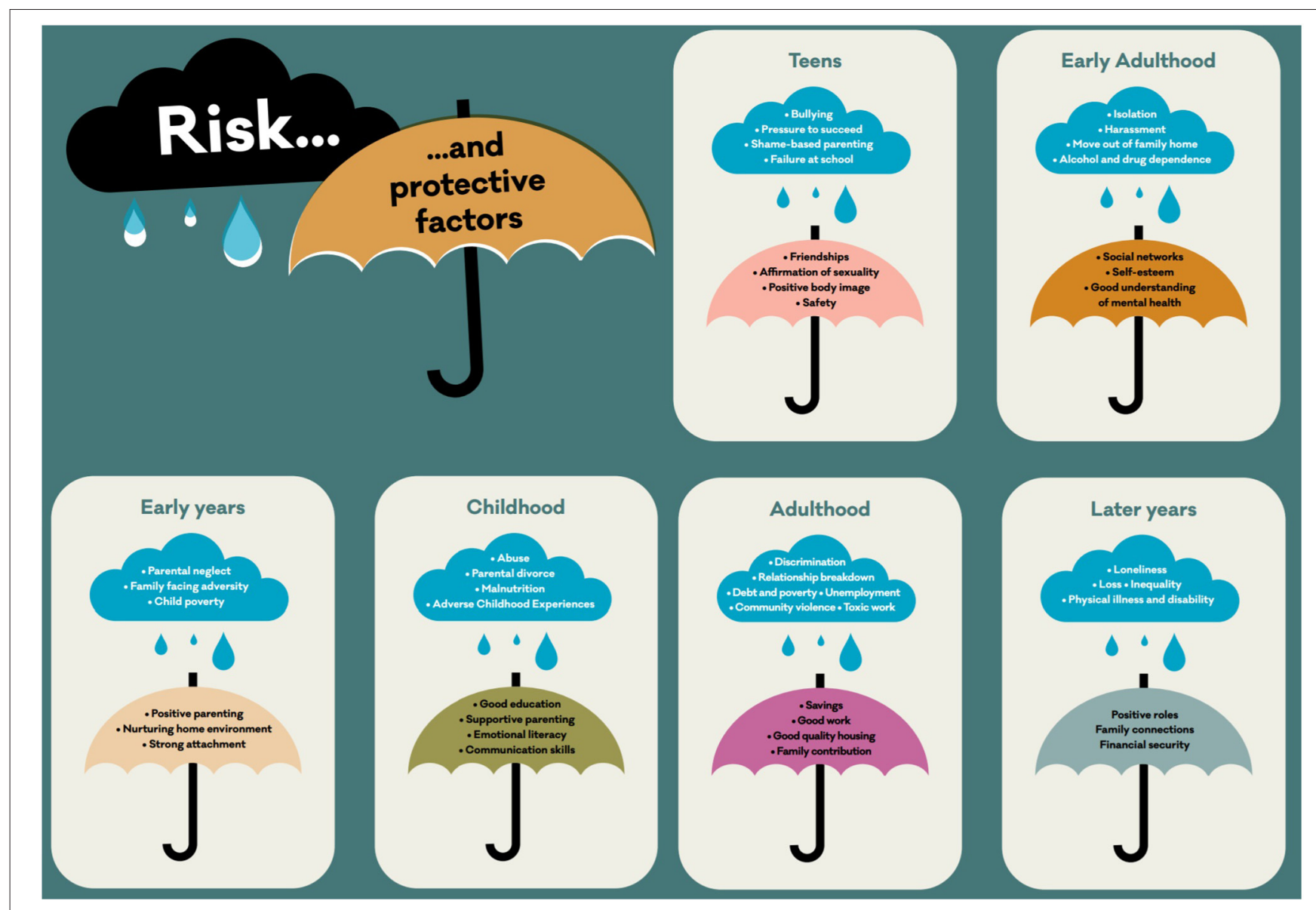

FIGURE 1 | Visualization of some indicative risk and protective factors across various stages of the course of life. (c) Kousoulis, Mental Health Foundation.

\section{FROM PUBLIC HEALTH TO PUBLIC MENTAL HEALTH}

Within public health there is indeed recognition that health is determined by a multi-dimensional and symbiotic relationship between the individual and the layers of their environment from the family home, through to the wider social and physical environment in which we live, including its cultural and political context. This describes a socio-ecological approach to health that has been advocated for almost three decades (6) and is still in line with the modern proposed definition of public health: "Public health is what we build together as a society when we shape our communities so everyone can achieve optimal health." (7).

This public health view has much to offer within a mental health context where there can be a tendency to focus attention on the individual in isolation from the social and ecological conditions in which they exist. Hence, applying such an approach to mental health would make sense given the established knowledge behind the social determinants of mental ill-health (8). While ecological approaches have been proposed before in association with rural workforce and family-focused practice (9), the built environment (e.g., urban design and planning, green space access), and the social environment (e.g., prosocial spaces, civic participation, cultural resources) of cities lend themselves well to a population mental health approach (10). It is expected then that this socio-ecological factor could be more readily applied in urban settings, which include a more limited and specific built environment and better defined authority and resources (11).

In fact, more than half of the world's population currently lives in cities, and the trend for further urbanization is rapidly increasing (12). However, cities do not work for everyone. The bond between health and place is broken. Health systems treat acute illness, while urban systems promote chronic distress (13). To turn the tide on creating healthy urban places, we need to influence the culture, structure, and beliefs that drive priorities and values for healthy places by recognizing that humans need to live with meaning, including having a sense of purpose and of being of value and having a place where they belong.

To facilitate this conversation, we are proposing a new visualization for the traditional socio-ecological model approach to help frame urban public mental health programs (Figure 2). 


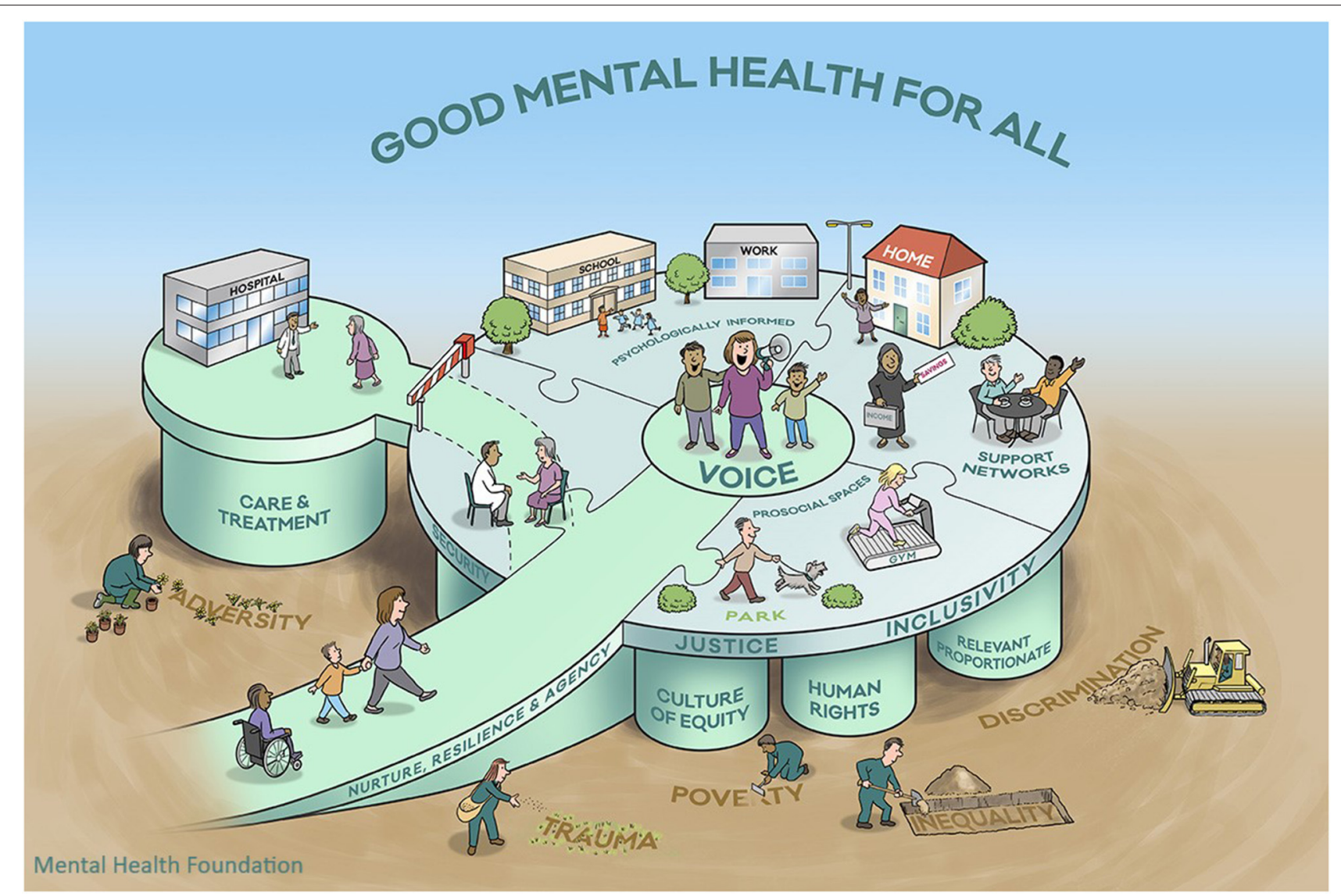

FIGURE 2 | Visualization of a whole-city socio-ecological model for public mental health. (c) Kousoulis, Goldie, Mental Health Foundation.

\section{DISCUSSION}

In creating this new visualization for a socio-ecological model in public mental health, we have respected representation of the following evidence so that the visual image should:

(1) Look at both the individual person and that person's environment, family, and community, as well as the wider structures, culture, and beliefs, taking a universally proportionate and culturally relevant approach across the whole life course (14).

(2) Be relevant to the environments that impact human development. These classically include four systems (15):

a) Microsystems: immediate social and physical surroundings (home, family, neighborhood, friendship groups);

b) Mesosystems: wider systems within the environment (schools, health care);

c) Exosystems: social, political and economic conditions (policy and legal environment including housing and welfare systems, cost, and standards of living);

d) Macrosystems: beliefs and attitudes shared by members of society (including stigma and prejudice, views on social justice, equality, and inclusion).

(3) Apply a Health in All Policies (HiAP) approach, as there are limitations to funding, planning, and developing solutions in a health service silo (16). Health needs to be understood as a central factor in not only our individual success but that of society. This is even more important in the consideration of mental health, which has a powerful and pervasive influence on our ability to perform and be productive across a range of areas.

(4) Adopt a Whole Communities Approach. This acknowledges that mental health improvement interventions must operate across multiple system levels. Much of the improvement impact will be experienced not only within the health system through a reduction in more acute and long-term mental health and social care support services, but also across systems that rely on social capital (workplaces, schools), the public support infrastructure (health and welfare systems, housing, community/urban planning, and regeneration), and those parts of the system that are the endpoint for those whose distress has not been addressed at an earlier stage (criminal justice, homelessness) (17).

(5) Draw from Socio-Ecological Systems Theory (18), by acknowledging the central influence of beliefs and ideologies across society in systems development, while taking account of the interconnections and dependencies among community members.

(6) Acknowledge the way in which stigma and discrimination shape the cultural context of how mental health is viewed 
and valued and the level of effort society members are willing to expend to address the adversity and structural risk factors behind this (5).

(7) Position the voice of those with lived experience of mental health problems at the core of any decision-making process and ensure coproduction (working in equal partnership) is championed in designing services, campaigns, or prevention programs (5).

We invite a critique and conversation in using this strongly evidence-informed visualization when taking whole-city approaches and modern public health service design.

\section{AUTHOR CONTRIBUTIONS}

All authors participated in the conception, drafting, and editing of the manuscript and are accountable for the content of the work.

\section{REFERENCES}

1. Kyu HH, Abate D, Abate KH, Abay SM, Abbafati C, Abbasi N, et al. Global, regional, and national disability-adjusted life-years (DALYs) for 359 diseases and injuries and healthy life expectancy (HALE) for 195 countries and territories, 1990-2017: a systematic analysis for the Global Burden of Disease Study 2017. Lancet. (2018) 392:1859922. doi: 10.1016/S0140-6736(18)32335-3

2. Wild CP. The exposome: from concept to utility. Int J Epidemiol. (2012) 41:24-32. doi: 10.1093/ije/dyr236

3. Gröger N, Matas E, Gos T, Lesse A, Poeggel G, Braun K, et al. The transgenerational transmission of childhood adversity: behavioral, cellular, and epigenetic correlates. J Neural Trans. (2016) 123:103752. doi: 10.1007/s00702-016-1570-1

4. Graham GN. Why your ZIP code matters more than your genetic code: promoting healthy outcomes from mother to child. Breastfeeding Med. (2016) 11:396-7. doi: 10.1089/bfm.2016.0113

5. Kousoulis A. Prevention and Mental Health. London: Mental Health Foundation (2019).

6. Evans RG, Barer ML, Marmor TR. Why are Some People Healthy and Others Not? The Determinants of the Health of Populations. New Jersey: Transaction Publishers (1994).

7. De Beaumont Foundation. PHRASES: Public Health Reach Across Sectors. (2020). Available online at: https://www.phrases.org/resource-library/ (accessed January 12, 2021).

8. Allen J, Balfour R, Bell R, Marmot M. Social determinants of mental health. Int Rev Psych. (2014) 26:392-407. doi: 10.3109/09540261.2014. 928270

9. Goodyear M, Maybery D, Reupert A, Allchin R, Fraser C, Fernbacher S, et al. Thinking families: A study of the characteristics of the workforce that delivers family-focussed practice. Int $J$ Mental Health Nursing. (2017) 26:238-48. doi: 10.1111/inm.1 2293

\section{FUNDING}

This work was sponsored by the Mental Health Foundation.

\section{ACKNOWLEDGMENTS}

We are grateful to Chris O'Sullivan and several colleagues at the Mental Health Foundation who have been part of conversations on conceptualizing and designing this model. We also thank our colleagues and partners at the International CIty and Urban Regional CoLlaborativE (iCircle) of the International Initiative for Mental Health Leadership (IIMHL) for comments and support including at the IIMHL 2018 exchange on Cities and Urban Regions. Permissions have been obtained to reproduce some of the text in this manuscript from the Mental Health Foundation's work, including published reports $(3,12)$. The Rich Picture model was produced by David Gifford, Inscript Design.

10. Belkin G, McCray C. ThriveNYC: delivering on mental health. Am J Public Health. (2019) 109:S156-63. doi: 10.2105/AJPH.2019.305040

11. Goldie I. Public Mental Health Today. London: Pavilion Publishing and Media (2010).

12. United Nations. Department of Economic and Social Affairs, Population Division. New York, NY: United Nations - World urbanization prospects (2015).

13. Moustaid E, Kornevs M, Lindencrona F, Meijer S. A system of systems of mental health in cities, digging deep into the origins of complexity. Adm Policy Ment Health. (2020) 47:961-71. doi: 10.1007/s10488-020-01035-0

14. Marmot M, Bell R. Fair society, healthy lives. Pub Health. (2012) 126:S410. doi: 10.1016/j.puhe.2012.05.014

15. Bronfrenbrenner U. The Ecology of Human Development. Boston, MA: Harvard University Press (1979).

16. World Health Organization. Health in All Policies: Helsinki Statement. Framework for Country Action. Geneva: World Health Organization (2014).

17. McDaid S, Kousoulis A. Tackling Social Inequalities to Reduce Mental Health Problems: How Everyone Can Flourish Equally. London: Mental Health Foundation (2020).

18. Cote M, Nightingale AJ. Resilience thinking meets social theory: situating social change in socio-ecological systems (SES) research. Prog Hum Geography. (2012) 36:475-89. doi: 10.1177/0309132511425708

Conflict of Interest: The authors declare that the research was conducted in the absence of any commercial or financial relationships that could be construed as a potential conflict of interest.

Copyright (C) 2021 Kousoulis and Goldie. This is an open-access article distributed under the terms of the Creative Commons Attribution License (CC BY). The use, distribution or reproduction in other forums is permitted, provided the original author(s) and the copyright owner(s) are credited and that the original publication in this journal is cited, in accordance with accepted academic practice. No use, distribution or reproduction is permitted which does not comply with these terms. 